\title{
SINCRONICIDADE ENTRE OS PRINCÍPIOS DA LIVRE INICIATIVA E VALORIZAÇÃO DO TRABALHO PELAS EMPRESAS TRANSNACIONAIS
}

\author{
Celso Ricardo Peel Furtado de Oliveira ${ }^{1}$ \\ Marcelo Freire Gonçalves ${ }^{2}$
}

Resumo: O presente artigo é resultado de pesquisa bibliográfica jurídico-teórica, com enfoque no método dedutivo para fins de abordagem do tema para defender a sincronicidade entre os princípios da valorização do trabalho e da livre iniciativa como elemento fundamental a ser observado pelas empresas transnacionais para que possam ser reconhecidas como eficientes e cumprir as regras do Pacto Global das Nações e seus Objetivos de Desenvolvimento Sustentável, para implantação de um capitalismo humanista.

Palavras-chave: valorização do trabalho humano; livre iniciativa; direito humanos; capitalismo humanista; empresas transnacionais.

\section{SYNCHRONICITY BETWEEN THE PRINCIPLES OF FREE ENTERPRISE AND VALUING WORK BY TRANSNATIONAL COMPANIES}

Abstract: This article is the result of a legal-theoretical bibliographic research, focusing on the deductive method for the purpose of approaching the theme to defend the synchronicity between the principles of valuing work and free enterprise as a fundamental element to be observed by transnational companies so they can be recognized as efficient and comply with the rules of the Global Compact of Nations and its Sustainable Development Goals, for the implementation of a humanist capitalism.

Keywords: valorization of human work; free initiative; human rights; humanist capitalism; transnational companies.

\section{Introdução}

O capitalismo, apesar de ser o sistema hegemônico no Ocidente, não conseguiu resolver os problemas da miséria e da desigualdade social no mundo vivendo na atualidade sua pior crise.

\footnotetext{
${ }^{1}$ Desembargador do Tribunal Regional do Trabalho de São Paulo. Professor Universitário. Mestre em Direito pela UNISANTA e Doutorando em Direito pela UNINOVE - celsopeel@ gmail.com.

${ }^{2}$ Desembargador do Tribunal Regional do Trabalho de São Paulo. Mestre e Doutor em Direito pela PUC. Professor do PPGD/Uninove - mfreiregoncalves@yahoo.com.br.
} 
A globalização ajudou a economia dos países desenvolvidos, mas pouco ajudou os países em desenvolvimento que continuam não se beneficiando integralmente do comércio internacional.

Com a globalização surgiram os grandes grupos transnacionais cuja participação é imprescindível para a efetivação de um mundo melhor, traduzido pelos princípios do Pacto Global das Nações Unidas.

As Nações Unidades, preocupada com o futuro do capitalismo e os efeitos da globalização apresentou o Pacto Global e a agenda 2030, com a responsabilidade social das empresas transnacionais consubstanciado nos ODS (Objetivos para o Desenvolvimento Sustentável) e suas metas, preconizando entre outros aspectos a necessidade do trabalho decente com a valorização do trabalho humano.

No cenário interno, a Constituição da República Federativa do Brasil preconiza a necessidade de harmonização dos valores sociais do trabalho e da livre iniciativa, na busca da eficiência da atividade econômica que só pode ser pensada com o respeito aos direitos humanos, na aplicação do caso concreto.

Somente com um capitalismo de face humanista, o que não é uma apenas uma opção ética, mas também uma imposição normativa, poderemos diminuir a miséria e pobreza no mundo, com a diminuição das desigualdades sociais.

A abordagem do objeto de estudo considera a discussão teórica sobre capitalismo, globalização, pacto global, objetivos de desenvolvimento sustentável, fundamentos e objetivos da república, valores sociais do trabalho, livre iniciativa, direitos humanos e justiça social.

2.Crise do Capitalismo.

A expressão capitalismo é definida como:

O sistema de produção cujos fundamentos são a empresa privada e a liberdade do mercado, sendo o objetivo principal a obtenção de lucro. Regime econômico caracterizado pelo grande desenvolvimento dos meios de produção cujo capital está centralizado em empresas privadas que contratam funcionários, pagando-lhes um salário. (DICIO, 2021) 
Giddens (2017) define capitalismo como "[...]sistema econômico originado no Ocidente baseado no intercâmbio comercial e na geração de lucro visando ao reinvestimento e crescimento dos negócios".

O sistema capitalista acabou prevalecendo no mundo, baseado no liberalismo econômico e na propriedade privada, sob a promessa que levaria prosperidade a humanidade.

Entretanto, o capitalismo está vivendo um momento de crise mundial, considerando que os beneficiários do crescimento econômico, com acesso as suas vantagens representam um pequeno número da população mundial continuando a grande maioria a viver em condições de pobreza e miséria.

Segundo dados atuais do IBGE (2021), a extrema pobreza atinge treze milhões e quinhentas mil pessoas e chegou ao maior nível em 7 anos.

Após um processo de desenvolvimento civilizatório, com a adoção do Estado de bemestar social nos países desenvolvidos, jamais usufruído na sua integralidade pela sociedade brasileira (BONAVIDES: 1991), estamos vivendo um momento de retrocesso, com a prevalência do neoliberalismo, acentuando o individualismo e egoísmo, com aumento da desigualdade social.

Com efeito, em pleno século XXI vivemos um paradoxo pois, apesar do reconhecimento dos direitos humanos, com forte crescimento econômico, ainda vivemos com a pobreza (SEN: 2010).

\section{Globalização}

A globalização consiste em trocas universais de informações, capitais e bens, definição esta que vai muito além de uma noção simplesmente econômica, ignorando fronteiras e produzindo um complexo emaranhado de interdependências transnacionais (FEAVER, 2009, pag 229).

Apesar da evolução sem precedentes em termos econômicos, sociais e tecnológicos, nem todas as nações do mundo se beneficiaram com o crescimento do comércio internacional resultante da globalização, mantendo-se afastados do desenvolvimento no cenário internacional, em especial no espaço latino-americano.

Com a globalização assistimos o surgimento de empresas transnacionais que, em muitos casos, possuem faturamento muito maior que o PIB da maioria dos países, podendo 
ser citadas como exemplos grandes corporações como Apple, Google, Microsoft, Facebook e Amazon.

Para Marcelo Benacchio (2019, pag. 25)

A globalização econômica é ditada pelas empresas transnacionais, que se fracionam
por diversos países na busca dos menores custos, com comando central na busca do
atendimento dos interesses de seus acionistas.

Em pesquisa realizada pela organização não governamental Global Justice Now, foi constatado que das 100 maiores entidades econômicas do mundo, 69 são empresas e apenas 31 são países, o que demonstra que o poder das corporações transnacionais está se expandindo cada vez mais rápido.

Para Global Justice Now:

(...) em busca lucros enormes, as grandes empresas muitas vezes fogem explorando as pessoas e o planeta. Os efeitos podem ser devastadores para comunidades em todo o mundo que são deslocadas para abrir espaço para novos projetos industriais ou exploradas em condições de trabalho brutais.

Não nos olvidamos que a atividade empresarial é fundamental para o desenvolvimento da sociedade, mas a atuação das corporações no mercado globalizado não pode ser pautada no interesse exclusivo dos acionistas, sem nenhuma preocupação social e sem ser pautada na promoção dos direitos humanos e da justiça social.

A globalização é um fenômeno inevitável e irreversível por meio do processo de internalização pela integração econômica com reflexos diretos nas relações econômicas, ambientais e sociais entre todos os países do mundo. (BAUMAN, 1999)

Ressalte-se que em função da globalização os países se reuniram em blocos econômicos com o objetivo principal do fomento do comércio internacional, buscando a livre circulação de bens e serviços dentro dos blocos e uma política externa comum em negociações comerciais com os demais blocos e países, visando o desenvolvimento econômico das respectivas regiões, como União Europeia, Mercosul e Nafta. 
Esses blocos não reduziram a influência desigual da globalização no mundo, ao contrário ressaltaram este fenômeno, tendo como exemplo o continente africano que continua sendo o mais pobre do planeta.

O capitalismo globalizado internacional faz lembrar as palavras de Keynes (1933, apud FRIEDEN, 2008, p. 49)

O decadente capitalismo internacional mas individualista nas mãos daquilo que nos tornamos após a guerra, não é um sucesso. Não é inteligente. Não é bonito. Não é justo. Não é eficaz. E não cumpre o que promete.

4. Livre Iniciativa e valorização do trabalho humano.

A Constituição traz no título VII da Ordem Econômica e Financeira, no capítulo I, art. 170, os princípios gerais da atividade econômica, estabelecendo que "[...] a ordem econômica, fundada na valorização do trabalho humano e na livre iniciativa [...]”.

Ora, o texto constitucional é claro que a ordem econômica deve ser fundada de forma concomitante na valorização do trabalho humano e na livre iniciativa, repetindo a mesma regra já explícita nos fundamentos da república, o que significa que não deve existir qualquer prevalência de um fundamento sobre o outro.

Com efeito, o constituinte foi mais longe, ao dispor que a finalidade da ordem econômica não está embasada no lucro e sim em “[...]...assegurar a todos existência digna[...]", devendo a livre iniciativa valorizar o trabalho humano com a finalidade de assegurar que os trabalhadores vivam com dignidade.

Por último, ainda deixa expresso que a livre iniciativa deve ser pautada pelos “[...]ditames da justiça social[...]".

Com efeito, a economia deve se adequar ao comando constitucional e não a norma jurídica a economia, esta escolha já foi feita pelo legislador constituinte, não cabendo ao aplicador e criador do direito infringir.

Leciona Eros Grau (2019, pag. 19) o direito é prescrito e o art. 170 da Constituição Federal estabelece que a ordem econômica:

(...) deve estar - vale dizer, tem de necessariamente estar - fundada na valorização do trabalho humano e na livre iniciativa, e de ter - vale dizer, tem de 
necessariamente ter - por fim assegurar à todos existência digna, conforme os ditames da justiça social.

Continua:

(...) a livre iniciativa não é tomada, enquanto fundamento da República Federativa

do Brasil, como expressão individualista, mas sim no quanto expressa de socialmente valioso" e “...no art. 170, caput, afirma-se que a ordem econômica deve estar fundada na valorização do trabalho humano e na livre iniciativa. Note-se, assim, que esta última é então tomada singelamente e aquele - o trabalho humano é consagrado como objeto a ser valorizado. (2019, pag. 20/21)

Newton de Lucca (2009, pag. 330) complementa que "as empresas devem exercer a liberdade econômica e a livre iniciativa com responsabilidade social não apenas pelo aspecto ético mas também em razão da norma jurídica".

Marcelo Benacchio (2018) defende que a regulação pelo Estado da atividade econômica tem a função distributiva dos benefícios resultantes do exercício da livre iniciativa, devendo estar associada à valorização do trabalhado humano e justiça social, com a distribuição da riqueza oriunda do trabalho humano.

Ressalte-se ainda que o Supremo Tribunal Federal, no RE 958.252 MG, de Relatoria do Min. Luiz Fux, reconheceu a relação dialógica entre os valores do trabalho e da livre iniciativa, sem a prevalência de um deles sobre o outro.

4. Os valores do trabalho e da livre iniciativa, insculpidos na Constituição (art. $1^{\circ}$, IV), são intrinsecamente conectados, em uma relação dialógica que impede seja rotulada determinada providência como maximizadora de apenas um desses princípios, haja vista ser essencial para o progresso dos trabalhadores brasileiros a liberdade de organização produtiva dos cidadãos, entendida esta como balizamento do poder regulatório para evitar intervenções na dinâmica da economia incompatíveis com os postulados da proporcionalidade e da razoabilidade.

Assim, a análise da ordem econômica constitucional é expressa ao determinar a necessidade de harmonização entre o exercício empresarial da livre iniciativa com a proteção e a valorização do trabalho humano. 


\section{Função Social}

O constituinte de 1988 foi expresso ao eleger a nossa república como um Estado Social ao dispor no art. $3^{\circ}$., como objetivos fundamentais do país construir uma sociedade livre, justa e solidária, com erradicação da pobreza e redução das desigualdades sociais.

A opção da Constituição Brasileira por um Estado Social e não Liberal, levou em conta que esta teoria política seria a única capaz de levar à paz e ao progresso solidário dos povos no século XXI.

Assim, considerando os fundamentos da ordem econômica, a valorização do trabalho e a livre iniciativa, estruturantes do sistema constitucional econômico, o Estado brasileiro tem o dever de promover intervenções, diretas ou indiretas, ativas e fomentadoras para o devido cumprimento principiológico.

Dentro desta perspectiva, as empresas possuem responsabilidade social, como um dos agentes da sociedade na busca da concretização do comando constitucional.

O Estado deve implementar políticas públicas, com a regulação necessária para garantir uma política econômica fundamentada na justiça social.

Calixto Salomão (2008, pag. 20) defende que a regulação pelo Estado, implica na organização e não atuação direta em atividades econômicas.

[...]a teoria da regulação, quando bem aplicada - exatamente o contrário do que tem ocorrido até o momento -, pode representar exatamente a contribuição mais útil de um Estado que decide retirar-se da intervenção econômica direita (através da prestação de uma gama bastante variada de serviços) para sua função de organizador das relações sociais e econômicas e que, por outro lado, reconhece ser, para tanto, insuficiente o mero e passivo exercício de um poder de polícia sobre os mercados.

Para Newton de Lucca (2009, pag. 328/329), as empresas tem responsabilidade social:

(...) implica assumir a plenitude da chamada responsabilidade social, vale dizer, a consciência de que todos nós temos em maior ou menor grau - como cidadãos, em geral, ou como empresários, em particular -, o indeclinável dever ético de pôr em prática as políticas sociais tendentes a melhorar as condições e a qualidade de vida de todos os nossos semelhantes. 
No mesmo sentido, o Prof. José Renato Nalini (2019, pag. 223):

A ética empresarial do século XXI traz o dever empresarial de se ocupar não apenas com os interesses estritos da empresa, com os de seus donos ou seus acionistas. Mas impõe uma preocupação abrangente, que envolva os viventes e também a posteridade. O mundo precisa ser mais justo, generoso e sustentável.

Nesse sentido, o art. $1^{\text {o }}$ da Constituição, traz como fundamento da República Brasileira, a soberania, a cidadania, a dignidade da pessoa humana, os valores sociais do trabalho e da livre iniciativa e o pluralismo político.

Todos esses fundamentos devem ser aplicados de forma conjunta, sem a prevalência de qualquer um deles, sendo certo que em relação aos valores sociais do trabalho e da livre iniciativa, não foram por acaso mencionados de forma conjunta dentro do mesmo inciso.

A intenção da Constituição foi ressaltar que deve existir uma sincronicidade entre ambos na aplicação e criação de norma jurídica, com a harmonização de duas garantias aparentemente conflitantes.

Aparente porque só existirá o conflito quando um deles prevalecer sobre o outro, por exemplo quando a livre iniciativa prevalecer sobre os valores sociais do trabalho, a justiça social e a proteção a dignidade da pessoa humana do trabalhador.

Trata-se de uma decisão política do legislador que não cabe ao aplicador ou criador da norma jurídica desrespeitar.

Para Eros Grau (2019, pag. 22):

São fundamentos da República, isto é, do Brasil, entre outros, o valor social do trabalho e o valor social da livre iniciativa. A ordem econômica (mundo do ser) deve estar fundada na valorização do trabalho humano e na livre iniciativa - a Constituição consagra, aí, valorização do trabalho humano e livre iniciativa, simplesmente. A livre iniciativa, ademais, é tomada no quanto expressa de socialmente valioso; por isso não pode ser reduzida, meramente, à feição que assume como liberdade econômica empresarial (isto é, da empresa, expressão do dinamismo dos bens de produção); pela mesma razão não se pode nela, livre iniciativa, visualizar tão somente, apenas, uma afirmação do capitalismo. Assim, livre iniciativa é expressão de liberdade titulada não apenas pelo capital, mas também pelo trabalho. 
Ressalte-se que compreendida a ética como os valores que devem reger o comportamento humano, tem grande importância nas relações de trabalho, considerando que a globalização aumentou a precariedade de vida dos trabalhadores, com a desvalorização reiterada da força do trabalho, com perda de renda, aceitando os trabalhadores novas colocações em péssimas condições de trabalho, traduzido pelo fenômeno flexibilização.

A flexibilização das condições de trabalho prioriza a atividade econômica em desfavor da valorização do trabalho humano, gerando uma sociedade empobrecida, não só sob o aspecto econômico como também de aspiração de melhoria, aumentando as desigualdades sociais.

A ética se traduz no comportamento de respeitar os direitos humanos, devendo ser observada nas políticas públicas, mas também pelo aplicador do direito. Não só pela empatia ao próximo, mas também pelo reconhecimento normativo da valorização do trabalho humano.

As corporações transnacionais devem exercer a liberdade da atividade econômica complementando as políticas públicas pelo respeito aos direitos humanos e da concretização da justiça social.

O constituinte escolheu um caminho, o Brasil é um Estado Democrático Humanista Social de Direito.

6.Capitalismo Humanista

Como vimos, o Estado brasileiro escolheu o capitalismo como sistema econômico, mas centrado nos direitos humanos, ou seja, um capitalismo com face humanista, tendo como centralidade a proteção a dignidade humana.

Para Sayeg e Balera (2019), direitos humanos e capitalismo não são antagônicos, devendo coexistir de forma sincronizada, a partir do crescimento econômico que garanta a sustentabilidade do planeta para as atuais e futuras gerações, com base num desenvolvimento fraterno. Não existe conflito entre Direito Econômico e Direitos Humanos (SAYEG: 2019).

Com efeito, em razão da necessidade da harmonização do sistema econômico capitalista com a nova ordem mundial, o desenvolvimento econômico não pode estar desassociado da proteção a pessoa humana. 
[...]processo de desenvolvimento deve centrar-se na pessoa humana e no planeta, visando garantir a todos os homens níveis básicos de subsistência e sustentabilidade planetária, com a decorrente livre realização das potencialidades individuais do homem e de todos os homens. É o "jus- humanismo antropofilíado - que busca ultrapassar a arraigada concepção antropocêntrica e positivista do direito no sentido de sistematizar a mais adequada regência jurídica da economia capitalista, mediante a evolução dos conceitos teóricos da realidade planetária.(BALERA, SAYEG, 2011).

Ademais, a corrente doutrinária do capitalismo humanista tem como base a fraternidade cristã, fundamentado no jusnaturalismo, com a finalidade de dar efetividade ao princípio maior da dignidade da pessoa humana, quando da aplicação do caso concreto, considerando o direito positivo na busca de uma concepção inclusiva do capitalismo.

Nesse sentido:

[...] capitalismo humanista, não possui o caráter antropocêntrico, ou seja, o homem no centro do universo, com os valores do individualismo, do racionalismo e do hedonismo essenciais para a caracterização do liberalismo. Ao contrário, o capital humanista, não dispensa o capital liberal, apenas o torna antropofilíaco, ou seja, é estruturado na Lei Universal da Fraternidade Cristã - do homem como valor fonte dos direitos humanos - de ter direito a ter direitos ao desenvolvimento, à paz, à cultura, à democracia, à liberdade, à igualdade, à vida - uma viga dignidade, de humanidade. (SANTOS: 2019, pag. 289)

O capitalismo humanista visa um desenvolvimento econômico pautado na fraternidade, com benefícios não só para atual, mas também as futuras gerações, com respeito aos direitos humanos como consolidado nos Objetivos de Desenvolvimento Sustentável da Agenda 2030 da Organização das Nações Unidas.

\section{Pacto Global das Nações Unidas}

A ideia de um Pacto Global envolvendo as empresas transnacionais e a Organização das Nações Unidas, surgiu em 1999, durante o Fórum Econômico Mundial, pelo Secretário-Geral da ONU, Kofi Anan, preocupado com o futuro da globalização e seus efeitos. 
Defendeu Kofi Anan (1999), no seu discurso de apresentação do Pacto Global, as empresas teriam, naquele momento duas escolhas de mundo:

Temos que escolher entre um mercado global movido apenas por cálculos de lucro de curto prazo e um que tem rosto humano. Entre um mundo que condena um quarto da raça humana à fome e miséria, e um que oferece a todos pelo menos a chance de prosperidade, em um ambiente saudável. Entre um vale-tudo egoísta em que ignoramos o destino dos perdedores, e um futuro em que os fortes e bem-sucedidos aceitam suas responsabilidades, mostrando visão global e liderança. ${ }^{3}$ (tradução livre)

Havia um sentimento da necessidade de incorporar as corporações transnacionais para concretização dos objetivos das Nações Unidas, considerando não só a necessidade de financiamento da ONU para suas ações, mas também para passar de um órgão internacional intergovernamental para uma organização global.

A proposta do Pacto Global das Empresas Transnacionais representa um projeto de dar uma face mais humana ao capitalismo, como garantia de prosperidade para futuras gerações, pela observância de valores e princípios de nas áreas dos direitos humanos, meio ambiente, direito do trabalho e combate a corrupção.

É composto de dez princípios, dois direitos humanos (respeitar e proteger os direitos humanos e impedir violações de direitos humanos) quatro princípios de direito do trabalho (apoiar a liberdade de associação no trabalho e negociação coletiva, abolir o trabalho forçado, abolir o trabalho infantil e eliminar a discriminação no ambiente de trabalho), três princípios de direito ambiental (apoiar uma abordagem preventiva aos desafios ambientais, promover a responsabilidade ambiental e encorajar tecnologias que não agridem o meio ambiente) e um princípio de contra a corrupção (combater a corrupção em todas as suas formas inclusive extorsão e propina).

Referidos princípios foram retirados de tratados internacionais já ratificados pela quase totalidade dos países, consubstanciados, respectivamente, na Declaração Universal dos Direitos Humanos (1948), Declaração de Princípios e Direitos Fundamentais no Trabalho

\footnotetext{
${ }^{3}$ We have to choose between a global market driven only by calculations of short-term profit, and one which has a human face. Between a world which condemns a quarter of the human race to starvation and squalor, and one which offers everyone at least a chance of prosperity, in a healthy environment. Between a selfish free-for-all in which we ignore the fate of the losers, and a future in which the strong and successful accept their responsibilities, showing global vision and leadership.
} 
(1998), Declaração da Conferência da ONU sobre Meio Ambiente e Desenvolvimento (1992) e pela Convenção das Nações Unidas contra a corrupção (2003).

As Nações Unidas, dando continuidade em seu projeto de erradicação da pobreza e promoção de uma vida digna para todos, aprovou a Agenda 2030, reunindo 17 Objetivos de Desenvolvimento Sustentável, compostos de 169 metas, visando o engajamento das empresas transnacionais para garantir de qualidade de vidas para as próximas gerações.

O objetivo 8 traz a sincronicidade entre a garantia de trabalho decente e crescimento econômico.

\section{Trabalho decente e crescimento econômico.}

Garante condições de trabalho decente para funcionários em toda a sua operação e na cadeia de negócios e suprimentos. Cria empregos decentes e formais em setores intensivos em mão de obra. Educa e treina para o trabalho.

Assim, todas as empresas transnacionais que integram o Pacto Global, assumem o compromisso da Agenda 2030, dos seus Objetivos de Desenvolvimento Sustentável e suas metas.

Apesar de não se tratar de um instrumento regulatório, trata-se de uma iniciativa voluntária que fornece diretrizes para a promoção do crescimento sustentável e de cidadania, assumindo as empresas a responsabilidade de contribuir para a concretização dos seus objetivos.

Nesse sentido Guilherme Amorim Silva, defende que deve existir uma colaboração entre os Estados e as empresas transnacionais na concretização de políticas públicas visando a efetividade dos objetivos da Agenda 2030.

Nesta medida, a força normativa que emana das normas previstas na Constituição da República, para além de seu caráter de articulação e direção, deverão compor importante espaço de vetor impositivo ao gestor de políticas públicas e definidor de orçamentos públicos para a eleição de prioridades e racionalização de medidas na consumação das tarefas em torno dos objetivos fundamentais da República consagrados no artigo 3o da Carta, papel que as empresas nacionais e transnacionais podem ocupar em colaboração com o Estado brasileiro por meio de instrumentos previstos, como vimos. (SILVA: 2018, pag. 121) 
7.1. Normas sobre as Responsabilidades das empresas transnacionais

Em 2003, a Subcomissão de Promoção dos Direitos Humanos da Comissão de Direitos Humanos das Nações Unidas, editou as Normas sobre responsabilidades das empresas transnacionais e outras empresas comerciais no campo dos direitos humanos.

Não possui natureza jurídica de tratado internacional, uma vez que os Estados não podem ratificar e, por consequência, não geram obrigações normativas vinculativas.

Entretanto, por terem origem na ONU, em razão do caráter dinâmico do direito internacional, a sua utilização pelos Estados, Empresas e Organização não governamentais podem imprimir caráter normativo, como uma norma de soft law e de direito consuetudinário.

Em relação a valorização do trabalho humano, discrimina as responsabilidades das empresas transnacionais, no exercício da livre iniciativa, constatando no item D:

\section{Direitos dos trabalhadores}

5. As corporações transnacionais e outras empresas comerciais não devem usar trabalho forçado ou obrigatório, conforme proibido pelos instrumentos internacionais relevantes e pela legislação nacional, bem como pelos direitos humanos internacionais e pelo direito humanitário.

6. As corporações transnacionais e outras empresas comerciais devem respeitar os direitos das crianças de serem protegidas da exploração econômica, conforme proibido pelos instrumentos internacionais relevantes e pela legislação nacional, bem como pelos direitos humanos internacionais e pelo direito humanitário.

7. As corporações transnacionais e outras empresas de negócios devem fornecer um ambiente de trabalho seguro e saudável conforme estabelecido nos instrumentos internacionais relevantes e na legislação nacional, bem como nos direitos humanos internacionais e no direito humanitário.

8. As corporações transnacionais e outras empresas de negócios devem proporcionar aos trabalhadores uma remuneração que garanta um padrão de vida adequado para eles e suas famílias. Essa remuneração deve levar em conta as necessidades de condições adequadas de vida, com vistas a uma melhoria progressiva.

9. As corporações transnacionais e outras empresas de negócios devem garantir a liberdade de associação e o reconhecimento efetivo do direito à negociação coletiva, protegendo o direito de estabelecer e, sujeito apenas às regras da organização em 
questão, de se associar a organizações de sua própria escolha, sem distinção, autorização prévia, ou interferência, para a proteção de seus interesses trabalhistas e para outros fins de negociação coletiva, conforme previsto na legislação nacional e nas convenções pertinentes da Organização Internacional do Trabalho.

Com efeito, toda a construção do Pacto Global, inclusive sobre as responsabilidades das empresas transnacionais visou harmonizar a livre iniciativa e atuação econômica das empresas transnacionais com o respeito e valorização do trabalho humano.

\subsection{Princípios Orientadores sobre empresas e direitos humanos}

Para aperfeiçoamento e efetividade do Pacto Global, em 2013, foram editados os Princípios Orientadores sobre Empresas e Direitos Humanos, denominados de Princípios Ruggie, em homenagem ao diplomata encarregado do programa John Ruggie, estabelecendo padrões para responsabilidade das empresas transnacionais e dos Estados na garantia dos direitos humanos, com base em três pilares norteadores: proteger, respeitar e remediar.

São 31 princípios orientadores para a eficácia dos respectivos pilares norteadores, diferenciando a responsabilidade dos Estados e das empresas, que não são excludentes e sim complementares.

- Dever do Estado de proteger os direitos humanos contra abusos por parte de empresas.

- Responsabilidade corporativa das empresas respeitarem os direitos humanos.

- $\quad$ Acesso das vítimas a recursos judiciais para remediar e reparar as violações de direitos humanos

De forma específica na área do direito do trabalho, consta no princípio 12 , relativo as empresas: 
12. A responsabilidade das empresas de respeitar os direitos humanos refere-se aos direitos humanos internacionalmente reconhecidos - entendidos, no mínimo, como aqueles expressos na Carta Internacional de Direitos Humanos e os princípios de direitos fundamentais estabelecidos na Declaração da Organização Internacional do Trabalho sobre os Princípios e Direitos Fundamentais no Trabalho.

Os princípios Ruggie visam coibir abusos e violações de direitos humanos por empresas, incentivando as corporações a adotarem políticas, inclusive, com edição de normas internas, visando evitar suas responsabilidades e impactos negativos da sua imagem, ou seja, tornar a empresa eficiente, trazendo-as para realização dos direitos humanos.

Não podemos falar mais em eficiência sem abranger o respeito aos direitos humanos.

\section{Considerações Finais}

Como tratamos no desenvolvimento deste ensaio, o capitalismo vive sua maior crise, uma vez que não entregou o prometido: a melhoria da condição social para toda a sociedade. Isso porque a maioria das pessoas não se beneficiam das vantagens trazidas pelo capitalismo e vivem na miséria e pobreza.

Com efeito, o sistema normativo constitucional é expresso em eleger a República Federativa do Brasil como um estado social democrático de direito que deve ser centrado nos direitos humanos.

A ordem econômica constitucional não é baseada no lucro e sim no respeito a liberdade econômica e livre iniciativa baseada na valorização do trabalho e com o objetivo da justiça social.

No âmbito internacional, as Nações Unidas, preocupada com o futuro do capitalismo e os efeitos da globalização lançaram o Pacto Global das empresas transnacionais, visando atrair as corporações para a efetividade dos direitos humanos sociais trabalhistas.

Os princípios do pacto global abrangem a valorização do trabalho humano, o que deve ser observado pelas empresas transnacionais dentro do exercício das suas atividades econômicas.

Posteriormente os objetivos do Pacto Global foram aperfeiçoados com as normas sobre as responsabilidades das empresas transnacionais e os princípios orientadores sobre empresa e direitos humanos, visando dar efetividade aos direitos humanos. 
O ideal é que a ONU edite uma resolução vinculativa para adoção do capitalismo humanista para diminuir a desigualdade social e combater a miséria e pobreza mas enquanto não é editada o ordenamento jurídico brasileiro já consagrou que a ordem econômica constitucional tem como fundamento a justiça social.

Somente com a sincronicidade entre a livre iniciativa e a valorização do trabalho humano, com o objetivo da justiça social teremos um capitalismo com face humanista, dentro da perspectiva do capitalismo humanista, visando garantir um mundo melhor para a atual e futura gerações.

Voltamos assim as palavras de Galeano, no sentido da harmonização e da sincronicidade entre a livre iniciativa e a valorização do trabalho humano deve ser uma busca utópica, sem fim, um caminhar constante na concretização dos direitos humanos.

Referências Bibliográficas:

ALSTON, Philip. A human rights perspective on the Millennium Development Goals, Disponível em: www.ohchr.org/english/issues/millenium-development/resources.htm. Acesso em 08.05.2021.

ARRUDA JÚNIOR, Antonio Carlos Matteis. Capitalismo Humanista \& Socialismo: o Direito Econômico e o Respeito aos Direitos Humanos. Curitiba: Juruá Editora, 2014.

ÁVILA, Pe. Fernando Bastos de. A Doutrina Social Cristã. $2^{a}$ Edição. São Paulo: Editora Santuário Aparecida, 2002.

BALERA, Wagner. Declaração sobre o direito ao desenvolvimento anotada. Curitiba: Editora Juruá, 2015.

BAUMAN, Zygmunt. Globalização: as consequências humanas. Rio de Janeiro: Jorge Zahar Ed., 1999.

BENACCHIO, Marcelo (coordenador), VAILATTI, Diogo Basílio e DOMINIQUINI, Eliete Doretto (organizadores). A sustentabilidade da relação entre empresas transnacionais e Direito Humanos. Curitiba: CRV, 2016. 
BENACCHIO, Marcelo. A ordem econômica constitucional e o exercício da atividade empresarial. In: Direito Empresarial: estruturas e regulação. Vol. 2 Renata Mota Maciel; André Lemos Jorge; João Maurício Adeodato. (Org.). São Paulo: Universidade Nove de Julho - Uninove, 2018.

BENACCHIO, Marcelo. Empresa e direitos humanos. In Coletânea da atividade negocial / organizadores: André Guilherme Lemos Jorge et al. - São Paulo: Universidade Nove de Julho - Uninove, 2019.

BONAVIDES, Paulo. Do Estado Liberal ao Estado Social. São Paulo: Editora Malheiros, 2013.

BONAVIDES, Paulo. História constitucional do Brasil. $3^{\text {a }}$ ed. Rio de Janeiro: Paz e Terra, 1991.

BRASIL. Constituição Federal de 1988. Disponível em: Disponível em: http://www.planalto.gov.br/ccivil 03/constituicao/constituicao.htm. Acesso em 11.06.2021.

BRASIL. IBGE. Síntese de Indicadores Sociais (SIS) Disponível em: https://censo2022.ibge.gov.br/2012-agencia-de-noticias/noticias/25882-extrema-pobrezaatinge-13-5-milhoes-de-pessoas-e-chega-ao-maior-nivel-em-7-anos.html. Acesso em 17 de junho de 2021.

BRASIL. STF RE 958.252 MG. Rel. Min. Luiz Fux.

Disponível em: https://redir.stf.jus.br/paginadorpub/paginador.jsp?docTP=TP\&docID=750817537. Acesso em 18.06.2021.

BRASIL. STF ADI 1950. Rel Min. Eros Grau.

Disponível em:

https://jurisprudencia.stf.jus.br/pages/search?classeNumeroIncidente=\%22ADI\%201950\%22

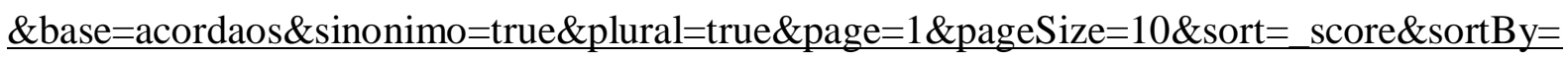
desc\&isAdvanced=true. Acesso em 18.06.2021. 
BRASIL. STF ADI 3512. Rel. Min. Eros Grau

Disponível

em:

https://jurisprudencia.stf.jus.br/pages/search?classeNumeroIncidente=\%22ADI\%203512\%22

$\underline{\text { base }}=$ acordaos $\&$ sinonimo $=$ true $\&$ plural $=$ true $\&$ page $=1 \&$ pageSize $=10 \&$ sort $=$ score $\&$ sortBy $=$ desc\&isAdvanced=true. Acesso em 18.06.2021.

BRASIL. STF RE 349.686. Rel. Min. Ellen Gracie.

Disponível

em:

https://jurisprudencia.stf.jus.br/pages/search?classeNumeroIncidente=\%22RE\%20349686\%2

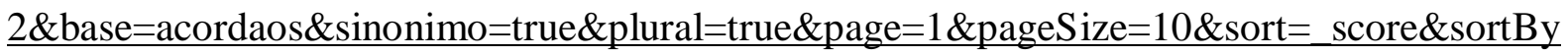
$=$ desc\&isAdvanced=true. Acesso em 18.06.2021.

DICIO. Dicionário On Line de Português. Disponível em: https://www.dicio.com.br. Acesso em: 15 junho 2021.

DUARTE, Juliana; PELLINI Jr. Crise Econômica, Demissões em Massa, Direitos Fundamentais e o Capitalismo Humanista. In Estudos do Capitalismo Humanista. Rio de Janeiro: Lumen Juris, 2017.

FEAVER, D. "Globaliation and national policy formation: an exploratory analysis" in critical persplectives on international business. Vol. 5 no. 3, pp.229-244, 2009. Disponível em: https://doi.org/10.1108/17422040910974703. Acesso em 08.05.2022.

FRIEDEN, Jeffry A. Capitalismo global: história econômica e política do século XX. Rio de Janeiro: Jorge Zahar Editor, 2008.

GIDDENS, Anthony. SUTTON, Philip W. Conceitos essenciais da Sociologia. $2^{\text {a }}$ Edição. Ebook. São Paulo: Editora Unesp, 2017.

GRAU, Eros Roberto. A ordem econômica na Constituição de 1988: interpretação e crítica. 19. ed. - São Paulo: Malheiros, 2018 
GRAU, Eros Roberto. Princípios da ordem econômica e empresa. In Coletânea da atividade negocial / organizadores: André Guilherme Lemos Jorge et al. - São Paulo: Universidade Nove de Julho - Uninove, 2019.

Global Justice Now. Ending Corporate Impunity. Disponível em: https://www.globaljustice.org.uk/our-campaigns/climate/ending-corporate-impunity/. Acesso em 10 de junho de 2021.

LUCCA, Newton De. Da Ética Geral à Ética Empresarial. São Paulo: Quartier Latin, 2009.

MICHALET, Charles-Albert. Que reste-t-il de Keynes pour comprendre la mondialisation? L'Économie politique, vol. No. 31, no. 3, (2006), pp. 59-70.

NALINI, José Renato. Ética empresarial. In Coletânea da atividade negocial. Organizadores: André Guilherme Lemos Jorge et al. - São Paulo: Universidade Nove de Julho - Uninove, 2019.

ONU. Normas sobre las responsabilidades de las empresas transnacionales y otras empresas comerciales em la esfera de los derechos humanos. Disponível em: file:///Users/celsopeel/Library/Mobile\%20Documents/com apple CloudDocs/E_CN.4_Sub.2 200312 Rev.2-ES.pdf. Acesso em 19.06.2021.

ONU. Un Global Compact. Disponível em: www.unglobalcompact.org. Acesso em 19.06.2021.

ONU. Objetivos de Desenvolvimento Sustentável - ODS. Disponível em: https://www.pactoglobal.org.br/ods. Acesso em 19.06.2021.

ONU. Discurdo de Kofi Ana da Apresentação do Pacto Global Disponível em: (https://www.un.org/sg/en/content/sg/speeches/1999-02-01/kofi-annans-address-worldeconomic-forum-davos Acesso em 10.06.2021. 
Oxfam International, 2009. «Le droit de survivre, le défi humanitaire du 21ème siècle», Disponível em: https://www.oxfam.org/sites/www.oxfam.org/files/droit-de-survivre-rapportfr.pdf. Acesso em 08.06.2021.

SAlOMÃO FILHO, Calixto. Regulação da Atividade Econômica (princípios e fundamentos jurídicos). 2a edição, Malheiros Editores, 2008.

SANTOS, Lucinéia Rosa dos e DUARTE, Juliana F. A. Globalização e Capitalismo Humanista. Revista de Direito Internacional e Globallização Econômica, Volume 1, número $1,2019$.

SEN, Amartya. Desenvolvimento como liberdade. São Paulo: Companhia das Letras, 2010.

SILVA, Guilherme Amorim Campos da. Constituição da República, empresa e desenvolvimento nacional. In: Direito Empresarial: Estruturas e Regulação. Volume 2. São Paulo: Uninove, 2018.

SAYEG, Ricardo. BALERA, Wagner. Fator CapH capitalismo humanista a dimensão econômica dos direitos humanos. São Paulo: Editora Max Limonad, 2019.

O Capitalismo Humanista. Filosofia Humanista de Direito Econômico. Petrópolis/RJ: Editora KRB, 2011. 